\title{
Nephropathy in Human Immunodeficiency Virus-1 Transgenic Mice Is Due to Renal Transgene Expression
}

\author{
Leslie A. Bruggeman, ${ }^{\star}$ Steven Dikman, ${ }^{\ddagger}$ Charis Meng, ${ }^{\star}$ Susan E. Quaggin, ${ }^{\S}$ Thomas M. Coffman, and Paul E. Klotman* \\ $*$ Divison of Nephrology and ${ }^{\ddagger}$ Department of Pathology, Mount Sinai Medical Center, New York 10029; ${ }^{\S}$ Division of Nephrology, Yale \\ University, New Haven, Connecticut 06510; and ${ }^{\| D i v i s i o n ~ o f ~ N e p h r o l o g y, ~ D u k e ~ U n i v e r s i t y ~ M e d i c a l ~ C e n t e r ~ a n d ~ D u r h a m ~ V A M C, ~ D u r h a m, ~}$ \\ North Carolina 27710
}

\begin{abstract}
HIV-associated nephropathy (HIVAN) is a progressive glomerular and tubular disease that is increasingly common in AIDS patients and one of the leading causes of end stage renal disease in African Americans. A major unresolved issue in the pathogenesis of HIVAN is whether the kidney disease is due to renal cell infection or a "bystander" phenomenon mediated by systemically dysregulated cytokines. To address this issue, we have used two different experimental approaches and an HIV-1 transgenic mouse line that develops a progressive renal disease histologically similar to HIVAN in humans. In the murine model, kidney tissue expresses the transgene and in heterozygous adults, renal disease develops shortly thereafter. We demonstrate by terminal deoxynucleotide transferase-mediated dUTP-biotin nick-end labeling assay that similar to the disease in humans, apoptosis of renal tubular epithelial cells is a component of the molecular pathogenesis. To determine whether apoptosis is due to transgene expression or environmental factors, we treated fetal kidney explants (normal and transgenic) with UV light to induce transgene expression. Apoptosis occurred in transgenic but not normal littermates after stimulation of transgene expression. To confirm a direct effect of HIV expression on the production of HIVAN, we transplanted kidneys between normal and transgenic mice. HIVAN developed in transgenic kidneys transplanted into nontransgenic littermates. Normal kidneys remained disease free when transplanted into transgenic littermates. Thus, the renal disease in the murine model is intrinsic to the kidney. Using two different experimental approaches, we demonstrate a direct effect of transgene expression on the development of HIVAN in the mouse. These studies suggest that in humans, a direct effect of HIV-1 expression is likely the essential cause of HIVAN, rather than an indirect effect of cytokine dysregulation. (J. Clin. Invest. 1997. 100:84-92.) Key words: HIV-associated nephropathy • apoptosis • chronic renal failure $\cdot$ glomerulosclerosis $•$ tubular interstitium
\end{abstract}

Address correspondence to Leslie A. Bruggeman, Division of Nephrology, Box 1243, Mount Sinai School of Medicine, One Gustave L. Levy Place, New York, NY 10029. Phone: 212-241-8002; FAX: 212987-0389; E-mail: lbrugge@smtplink.mssm.edu

Received for publication 16 January 1997 and accepted in revised form 1 April 1997.

The Journal of Clinical Investigation

Volume 100, Number 1, July 1997, 84-92

\section{Introduction}

Human immunodeficiency virus-associated nephropathy (HIVAN, ${ }^{1}$ reviewed in references $1-3$ ) is a complication in $\sim 10 \%$ of African American AIDS patients (4, 5). HIVAN has been reported to occur at any point in AIDS progression with no apparent correlation with viral burden or CD4+ T cell number $(1,6,7)$. Clinically, HIVAN is characterized by heavy proteinuria and rapid progression to end stage disease. Renal biopsy material generally reveals both glomerulosclerosis and tubulo-interstitial lesions, with extensive epithelial cell injury and microcystic tubular dilation. Hyperplasia of both tubular and glomerular visceral epithelium can be observed in addition to increased deposition of extracellular matrix in the mesangium and tubulointerstitium.

One of the fundamental questions that remains to be answered is whether HIVAN is caused by infection of renal cells or is a secondary phenomenon due to HIV-1 infection at another site. Although initial studies were inconclusive as to whether renal cells were infected (8-11), recent studies have provided stronger evidence that renal cell infection may occur $(12,13)$. Likewise, several cytokines are released by HIV-1infected lymphocytes and are present at high systemic levels including, IL-1, IL-6, interferon $\gamma$, basic fibroblast growth factor, transforming growth factor $\beta$, tumor necrosis factors $\alpha$ and $\beta$ (14). Many of these cytokines have been implicated as pathogenic in both in vitro and in vivo models of renal disease (15, 16). Not surprisingly, the pathological basis for HIVAN has centered on these two issues: $(a)$ a direct effect of HIV-1 versus $(b)$ an indirect effect of the dysregulated cytokine milieu.

In the present manuscript, we describe studies addressing this issue using two different experimental approaches based on observations in humans and in the murine model. In humans, the tubulointerstitial lesion and the formation of microcysts is the prominent pathogenic feature of HIVAN. Recently, apoptosis has been found to be a common mechanism of tubule damage in many different renal diseases including congenital polycystic disease, obstructive uropathy, hypertension, crescentic glomerulonephritis, and ischemic renal disease (17-20). Apoptosis or programmed cell death is also an important feature in kidney development and regeneration $(21,22)$. Previous studies with knock-out mice for $b c l-2$, a gene which protects from apoptosis, reveal normal development of almost all organs except the kidney (23). The $b c l-2$ null mice develop polycystic kidneys and renal failure similar to autosomal dominant polycystic kidney disease, and this study suggests that the

1. Abbreviations used in this paper: HIVAN, HIV-associated nephropathy; HPF, high power field; LTR, long terminal repeat; NBT, nitroblue tetrazolium salt; TUNEL, terminal deoxynucleotide transferase-mediated dUTP-biotin nick-end labeling. 
loss of this protective mechanism for apoptosis may contribute to renal tubule pathogenesis (24).

Apoptosis is an important feature of cell death associated with HIV infection. After exposure to HIV-1 envelope protein, T cells undergo apoptosis (25). In a recent study using biopsy material from patients with HIVAN, apoptotic nuclei could be detected in both the interstitium and the tubules (26). Glomeruli in contrast, had little evidence of apoptotic change. Similarly, glomeruli from patients with different forms of nephropathy had very few apoptotic cells. This suggests that abnormal apoptosis either during development or in disease may be a critical mechanism for renal tubule damage and the development of micro or macrocysts.

In this study, we used two approaches to the HIV-1 transgenic mouse model to demonstrate that expression of the viral transgene in renal cells and not exposure to the circulating milieu is sufficient to induce the features of HIVAN. Using ex vivo fetal transgenic kidneys we demonstrate that transgene expression induces apoptosis in renal tubular structures. Using reciprocal transplantation of transgenic and normal kidneys into normal and transgenic mice, we demonstrate that the histological features of HIVAN develop only when the kidneys are transgenic. These studies support the hypothesis that a direct effect of HIV-1 gene products or even possibly HIV-1 infection of the kidney causes HIVAN.

\section{Methods}

Transgenic mice. The development of the transgenic mouse line $\mathrm{TgN}(\mathrm{pNL} 43 \mathrm{~d} 14) 26 \mathrm{Lom}$ ("Tg26") has been reported previously (27, 28). These mice contain 10 copies of the HIV-1 proviral DNA pNL4$3 \mathrm{~d} 1443$ under the transcriptional control of the native long terminal repeat (LTR). The transgene was generated by deletion of a $3-\mathrm{kb}$ SphI/BalI fragment within pNL4-3 spanning the gag and pol genes, rendering this construct nonreplicating and noninfectious $(27,28)$. We have previously shown the homozygous and heterozygous mice develop multiple phenotypes including a progressive renal disease in heterozygotes (28), a wasting syndrome (29), a myopathy and myositis in homozygotes (30), and skin lesions and cataracts (31). We have also previously documented the pattern of transgene expression in the kidney and other tissues $(28,32)$. The transgenic animals used for these studies were from an inbred colony (over seven generations) established at Mount Sinai using animals obtained from the original National Institutes of Health (NIH) colony. In the Mount Sinai colony, all phenotypes and genotypes (as determined by restriction fragment length polymorphisms) have not changed when compared with the original colony. Inbreeding in our colony has, however, increased the penetrance of the phenotype of renal disease to $100 \%$ of adult animals when compared with our previous report of $60 \%$ at the NIH (28) when the animals were not strictly inbred. All studies using mice were approved by the Institutional Animal Care and Use Committees of Duke University and Mount Sinai Medical Centers.

Light microscopy. Kidneys from adult normal and heterozygous transgenic mice with and without disease were prepared for light microscopy. Kidneys were fixed in $4 \%$ paraformaldehyde (PFA)/PBS overnight and 4- $\mu \mathrm{m}$ paraffin sections were stained with hematoxylin and eosin. Apoptotic nuclei were counted in three sections per specimen, five high power fields (HPF) per each section from normal mice $(n=7)$, transgenic mice with $1+$ proteinuria $(n=7)$, and transgenic mice with edema $(n=7)$. The total number of glomeruli observed in each group were 105 in the normals, 99 in the transgenics with $1+$ proteinuria, and 60 in the transgenics with edema. Analysis of variance was performed and all numbers with a $P$ value $<0.05$ were subjected to Fisher's post hoc test to determine critical difference (Statview 4.0.1, Abacus Concepts Inc., Berkeley, CA).
Embryo culture. Day 12 fetuses were dissected from pregnant Tg26 heterozygous mice and both kidneys were removed. Pups from three pregnant Tg26 heterozygotes were obtained and two litters (15 pups total) were used for in situ hybridization and one litter (eight pups) was used for electron microscopy. DNA was extracted from the remainder of each fetus and used for Southern blot analysis to identify transgenic and nontransgenic fetuses as previously described (33). Each kidney was placed in a separate $35-\mathrm{mm}$ tissue culture dish with ME/ Ham F12 plus 10\% FBS and cultured for $7 \mathrm{~d}$ (34). At days 3 and 5, one of each pair was exposed to $12.5 \mathrm{~J} / \mathrm{m}^{2} \mathrm{UV}$ light $(254 \mathrm{~nm})(35)$. At the end of the culture period, kidneys were either fixed for electron microscopy in $3 \%$ glutaraldehyde/PBS or processed for in situ hybridization.

Terminal deoxynucleotide transferase-mediated dUTP-biotin nickend labeling assay. Adult mouse kidneys were fixed for $4 \mathrm{~h}$ in $4 \%$ PFA/PBS followed by freezing in OCT compound (Tissue-Tex; Miles Inc., Elkart, IN). Frozen sections $(10 \mu \mathrm{m})$ were incubated with terminal deoxynucleotide transferase and FITC-dUTP as described (36).

In situ hybridization. The RNA expression plasmids pGM92 and pGM93 were obtained from the NIH AIDS Research and Reference Reagent Program (contributed by John Rossi). These plasmids contain (in opposite orientations) $1.1 \mathrm{~kb}$ of the $3^{\prime}$ end of the HIV-1-coding region that is common to all HIV-1 mRNAs. Both plasmids were digested with EcoRI and sense and antisense transcripts were synthesized using T7 and digoxigenin-UTP using a kit from Boehringer Mannheim (Genius; Indianapolis, IN). The probes were cleaved with alkali to $\sim 500$-bp fragments as recommended by the manufacturer.

Fetal kidney tissue was fixed for $30 \mathrm{~min}$ in $4 \%$ PFA/PBS and then transferred to $30 \%$ sucrose/PBS overnight. Adult kidneys were bisected and fixed for $2 \mathrm{~h}$ in $4 \%$ PFA/PBS. Fixed tissue was blocked in paraffin and cut into 4- $\mu \mathrm{m}$ sections and mounted onto poly L-lysine coated, RNase-free slides. In situ hybridization was carried out using a digoxygenin-antidigoxygenin technique as described previously (Wilson, P.D., O. Deruyst, L. Gatti, D. Falkenstein, S. Robinson, D. Fambrough, and C.R. Burrow, manuscript submitted for publication) and with the following modifications. After hybridization and washing, slides were treated with $20 \mu \mathrm{g} / \mathrm{ml} \mathrm{RNase}$ for $30 \mathrm{~min}$ at $37^{\circ} \mathrm{C}$, followed by two washes in $0.2 \times \mathrm{SCC}$ at $37^{\circ} \mathrm{C}$. A 4 -h incubation with 1 $\mathrm{mM}$ levamisole was also included before blocking with sheep serum. Color development was with 5-bromo-4-chloro-3-indolyl phosphate (BCIP) and nitroblue tetrazolium salt (NBT; Boehringer Mannheim). Sections were quantitated by counting the number of positively stained cells in at least three high power fields per each specimen.

Kidney transplantation. To further examine the relative contributions of renal versus circulating factors in the pathogenesis of HIVAN, we performed kidney cross-transplantation experiments. To determine the role of renal expression of HIV-1 genes in isolation, kidneys from heterozygous HIV-1 transgenic mice were transplanted into nontransgenic littermates $(n=2)$. Conversely, to examine the role of systemic HIV-1 expression in the pathogenesis of HIVAN, kidneys from nontransgenic donor mice were transplanted into heterozygous HIV-1 transgenic littermates $(n=2)$. Transplantation of fully vascularized mouse kidney grafts, followed by bilateral native nephrectomy was performed as described previously (37). Proteinuria was assessed in donor and recipient mice before transplantation using Chemsticks (trace to $3+$ scale), and monitoring was continued for up to $24 \mathrm{wk}$ after transplantation. After $24 \mathrm{wk}$, animals were killed and the kidney grafts were harvested and fixed in PFA/PBS. Hematoxylin and eosin-stained thin sections were prepared and examined for the presence of histomorphological abnormalities.

\section{Results}

Apoptotic changes in diseased kidneys. HIV-1 transgenic mice develop a progressive renal disease similar to HIVAN with microcystic tubular interstitial disease. On light microscopy, dilated tubules in adult transgenic mice had evidence of epithelial cells undergoing apoptosis. These cells exhibit con- 

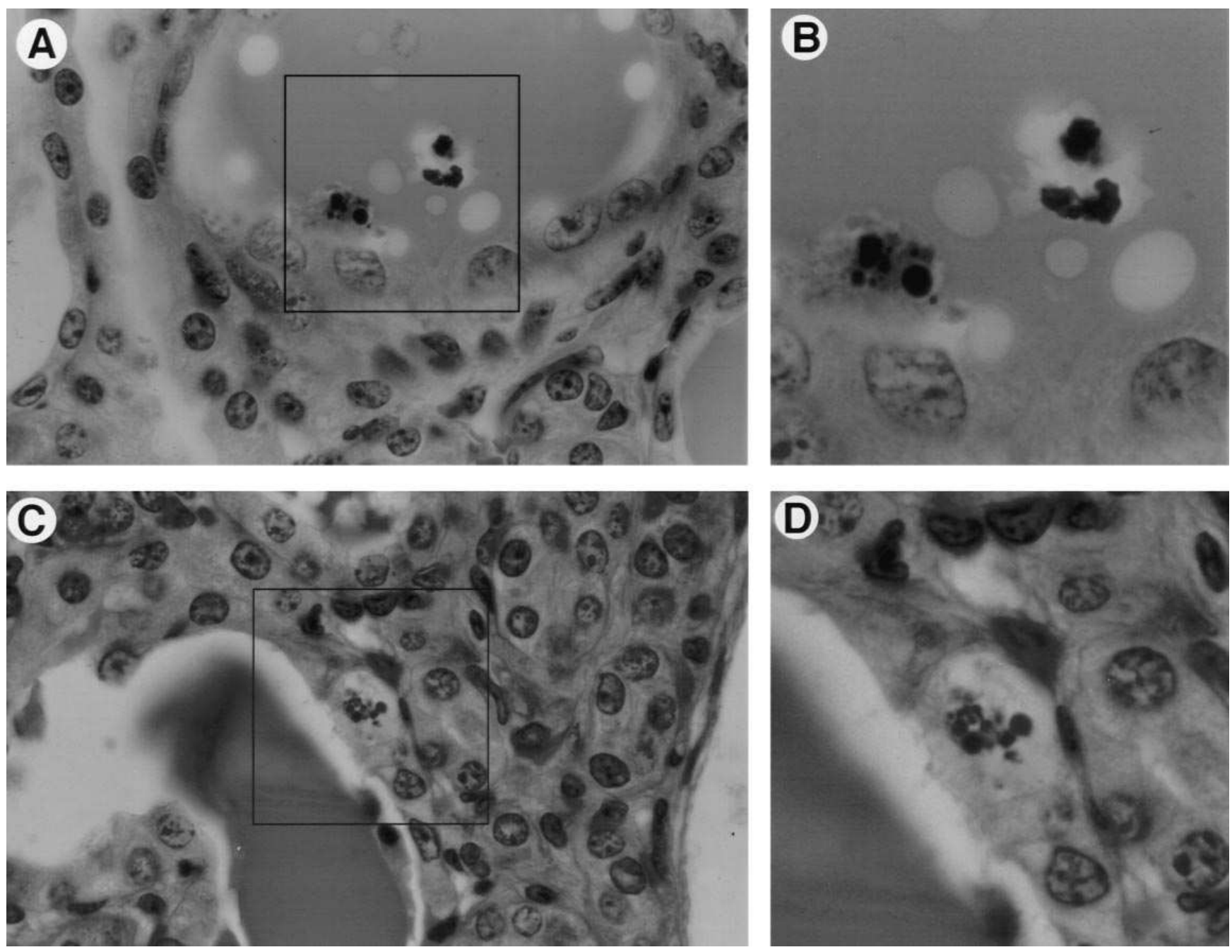

Figure 1. Identification of apoptotic epithelial cells in adult transgenic mouse kidneys with HIVAN. (A) Epithelial cell being sloughed into a dilated tubule lumen containing a proteinacious cast. $(B)$ Magnification of boxed region in $A$ showing chromatin condensation into apoptotic bodies. $(C)$ Cell contiguous with the epithelial cells lining a dilated tubule containing a proteinacious cast. $(D)$ Magnification of boxed region in $C$ showing chromatin condensation into apoptotic bodies. Hemotoxylin and eosin stain, original magnification of 250.

densed and fragmented chromatin typical of apoptotic cell death (Fig. 1). Normal adult kidneys had $0.179 \pm 0.042(P<$ 0.02) apoptotic cells/HPF as compared with $0.764 \pm 0.090(P<$ $0.001)$ in adult transgenic kidneys with early stages of disease $(1+$ proteinuria). Edematous mice with end stage disease had $2.730 \pm 0.187(P<0.001)$ apoptotic cells/HPF. Apoptosis was almost exclusively observed in tubules with only rare apoptotic cells observed in glomeruli from transgenic kidneys.

To confirm these renal epithelial cells were apoptotic, kidneys from adult animals with end stage disease were evaluated for the presence of apoptotic cells using the terminal deoxynucleotide transferase-mediated dUTP-biotin nick-end labeling (TUNEL) assay. The TUNEL assay detects DNA fragmentation by fluoresceinating the free ends of the DNA such that cells undergoing apoptosis can be detected by fluorescence microscopy. Light microscopy of an unstained frozen section of adult, diseased kidney shows both a glomerulus and tubules (Fig. $2 \mathrm{~A}$ ). The TUNEL assay from this region (Fig. $2 C$ ) had a significant number of apoptotic cells, predominantly in the areas of microcysts with little apoptosis observed in glomeruli. Normal adult kidneys typically had only rare apoptotic cells
(Fig. 2 B). The results of the TUNEL assay suggested that transgene expression in the kidney may induce apoptosis in the tubular epithelial cells.

Transgene expression in adult kidney. Previous studies evaluating transgene expression using Northern analysis and reverse transcriptase polymerase chain reaction indicated that the kidney expresses the transgene with peak expression near weaning age (28). Since these studies used mRNA prepared from intact kidneys, the specific cell types contributing to the transgene mRNA pool was unknown. To determine which cell types within the kidney express the transgene, in situ hybridization on adult kidneys was performed (Fig. 3). Transgene expression was detected in both cortex and medulla. Sporadic cells in the glomerulus and Bowman's capsule were positive. However, the majority of staining was in the tubular epithelium with some staining in the tubular interstitium. Thus, cell types with higher levels of transgene expression correlated with the cell types undergoing apoptosis.

Transgene expression induces apoptosis. To determine whether apoptosis was caused by alterations in cytokines that are known to affect apoptosis or by a direct effect of HIV-1 gene 


\section{unstained frozen section}
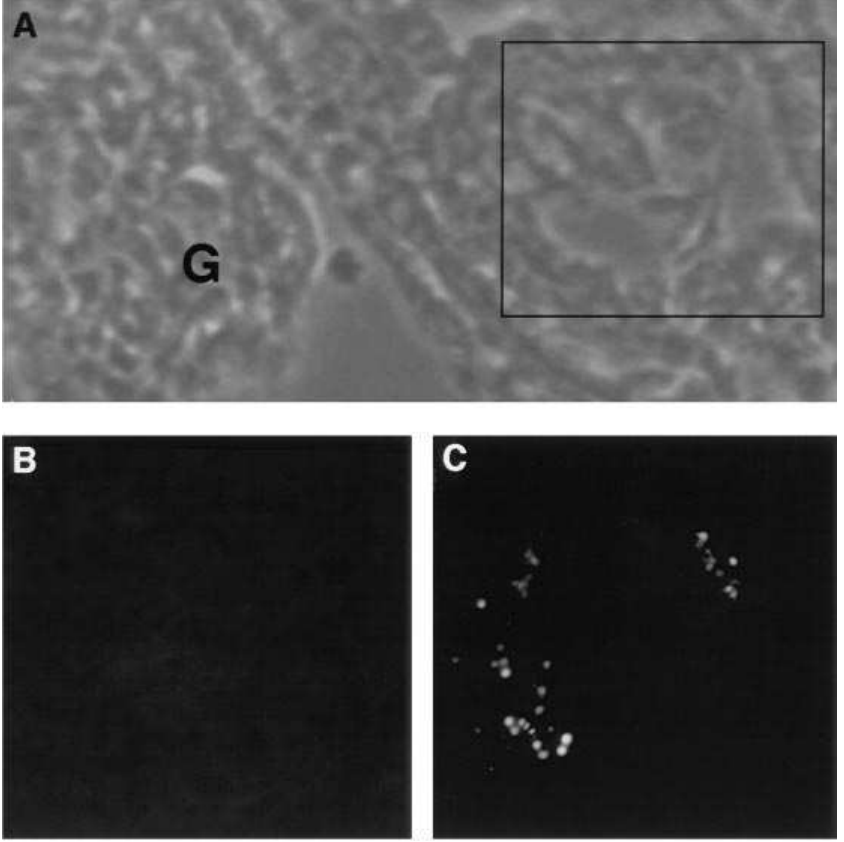

non-transgenic control

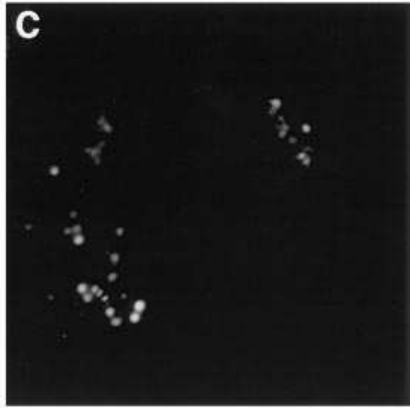

transgenic

expression, we cultured kidneys ex vivo. Whole organ culture can only be accomplished in fetal tissue and we have previously shown transgene expression during fetal development (33). Day 12 fetal kidneys from transgenic and normal fetuses were grown in culture for $7 \mathrm{~d}$ and developed normally. To increase transgene expression, fetal kidneys were irradiated with UV light to directly upregulate transcription of the HIV-1 LTR. Fetal kidneys treated with UV light had elevated steadystate levels of viral mRNA as confirmed by in situ hybridization (Fig. 4). Expression of the transgene was evident at a low level in the unirradiated kidneys (Fig. $4 \mathrm{~B}$, average of five cells/ HPF, but was enhanced sixfold in the UV stimulated tissue (Fig. $4 C$, average of 30 cells/HPF).

Apoptosis in the UV irradiated kidneys was increased as detected by light and electron microscopy. Light microscopic comparisons of the irradiated and unirradiated kidneys showed

Figure 2. Identification of apoptotic cells in transgenic mouse kidneys by TUNEL assay. TUNEL assay was performed on adult, diseased transgenic, and nontransgenic mice. $(A)$ Unstained frozen section; "G," glomerulus. $(B)$ TUNEL fluorescence of a nontransgenic control in region of tubules. $(C)$ TUNEL fluorescence in transgenic kidney corresponding to the boxed region of panel $A$ exhibiting tubular dilatation.

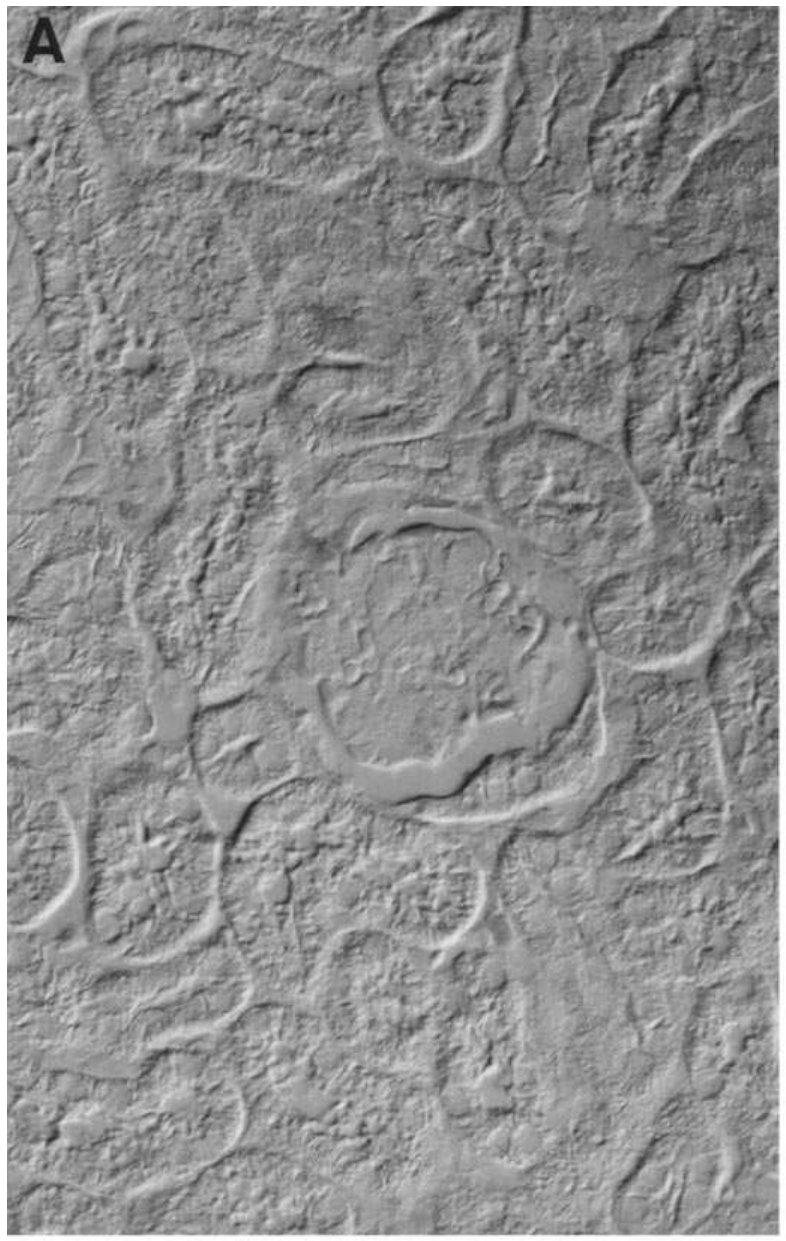

sense

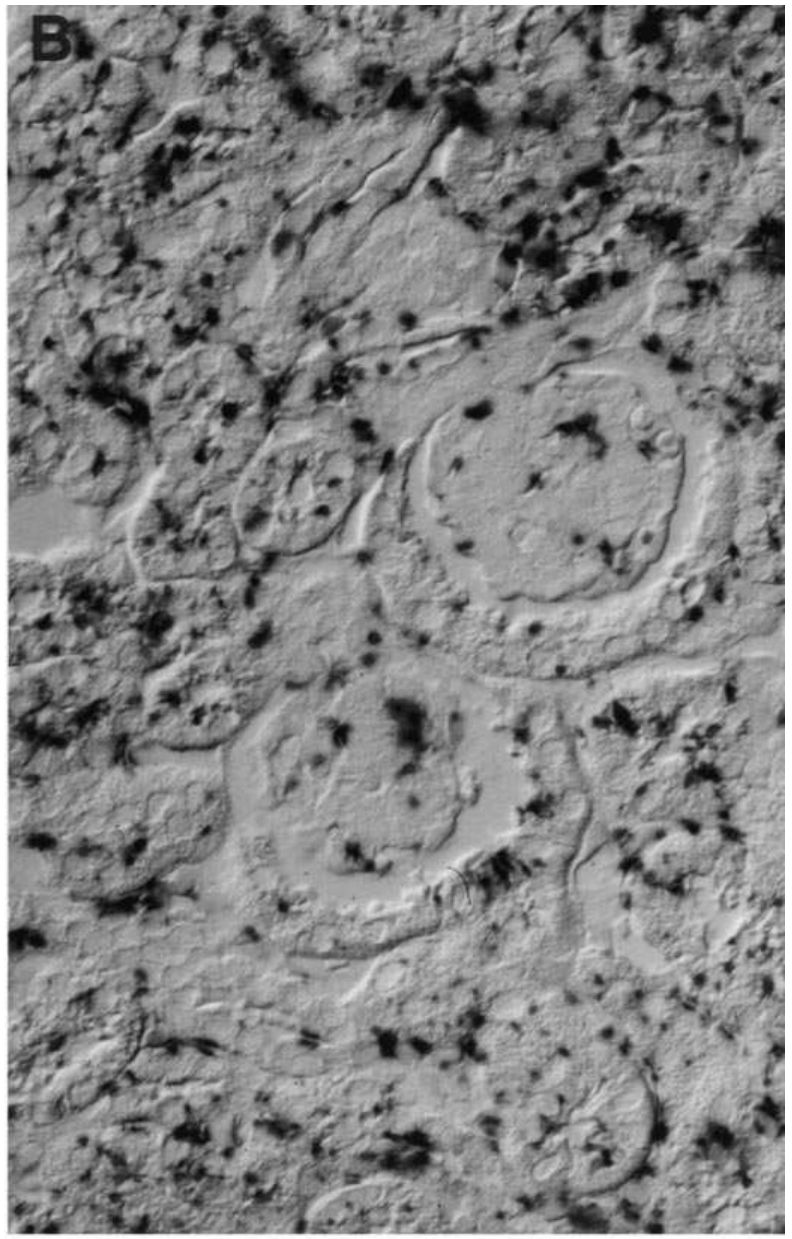

antisense

Figure 3. In situ hybridization of kidney transgene expression. Adult kidney from a weanling age animal with $1+$ proteinuria. $(A)$ Sense control probe. (B) Antisense probe. Original magnification of 100. 


\section{Transgenic}

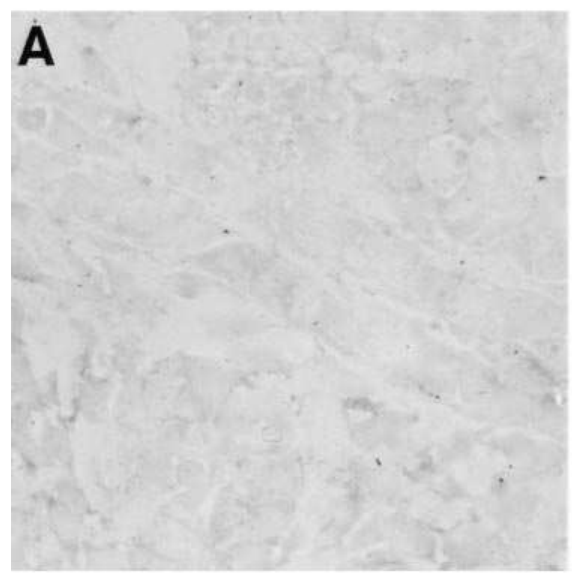

sense
Transgenic

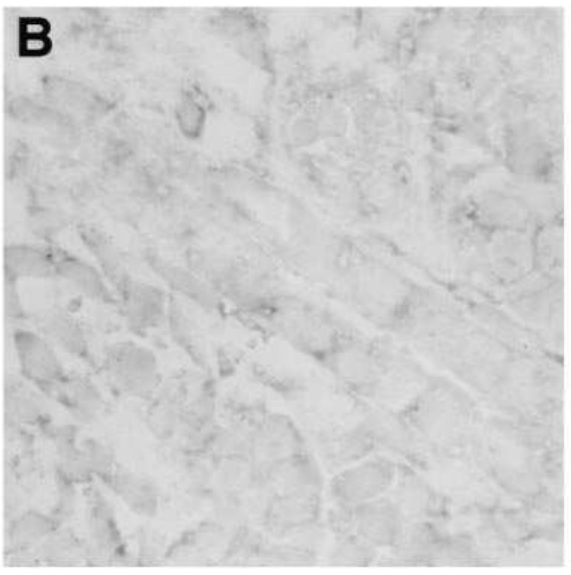

antisense
Transgenic + UV

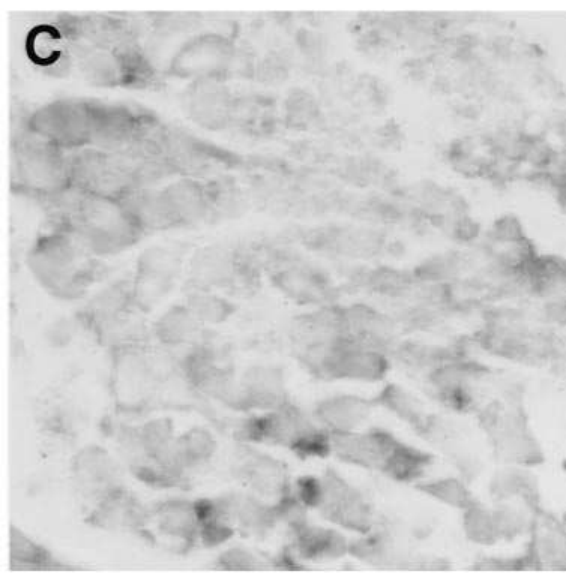

antisense

Figure 4. In situ hybridization of HIV-1 transgenic and UV-irradiated cultured kidneys (fetal day 12). (A) Unirradiated HIV-1 transgenic kidney with control probe (sense). (B) Unirradiated HIV-1 transgenic kidney with antisense probes (serial section with panel $A$ ). (C) UV irradiated HIV-1 transgenic kidney with antisense probes showing elevation in steady-state mRNA levels from unirradiated. Original magnification of 250.

dark staining aggregates in the transgenic kidneys irradiated with UV light (Fig. 5). The number of apoptotic nuclei in the irradiated transgenic kidney averaged 26 cells/HPF, a minimum twofold increase over unirradiated transgenic or irradiated normal kidneys. Because large clusters of apoptotic nuclei were detected in the luminal space of the developing comma bodies after irradiation, an exact apoptotic cell number was impossible to determine (see Fig. $5 \mathrm{C}$ ). Electron micrographs of the dark staining material showed condensed and fragmented nuclei with a centrifugal pattern of condensation on the nuclear membrane, and many dense chromatin masses which form due to the disintegration of the nucleus (Fig. 6). These typical apoptotic changes were most evident in comma and S-shaped bodies, areas of tubule formation. These changes were not observed in nontransgenic or unirradiated transgenic kidneys. Since fetal kidney culture was performed in the absence of potential circulating factors, these results suggest transgene expression in renal cells alone is sufficient to induce apoptosis in the tubular epithelium.

Renal cross-transplantation. To establish the role of renal transgene expression in the development of renal disease in vivo, we performed reciprocal kidney transplantation between normal and transgenic mice. To examine the role of renal factors in the pathogenesis of HIVAN, we transplanted kidneys from heterozygous HIV-1 transgenic mice into nontransgenic littermates. Histological examination of the contralateral kidney, harvested from the transgenic mouse donors at the time of surgery (Fig. 7, $A$ and $B$ ), showed modest abnormalities that suggested early focal glomerulosclerosis; no microcystic changes were observed. One of the nontransgenic mice that received a transplant kidney from a transgenic donor became edematous and moribund with $3+$ proteinuria and was killed. At the time of death, the blood urea nitrogen was $302 \mathrm{mg} / \mathrm{dl}$ and the transplant kidney manifested marked histological changes that
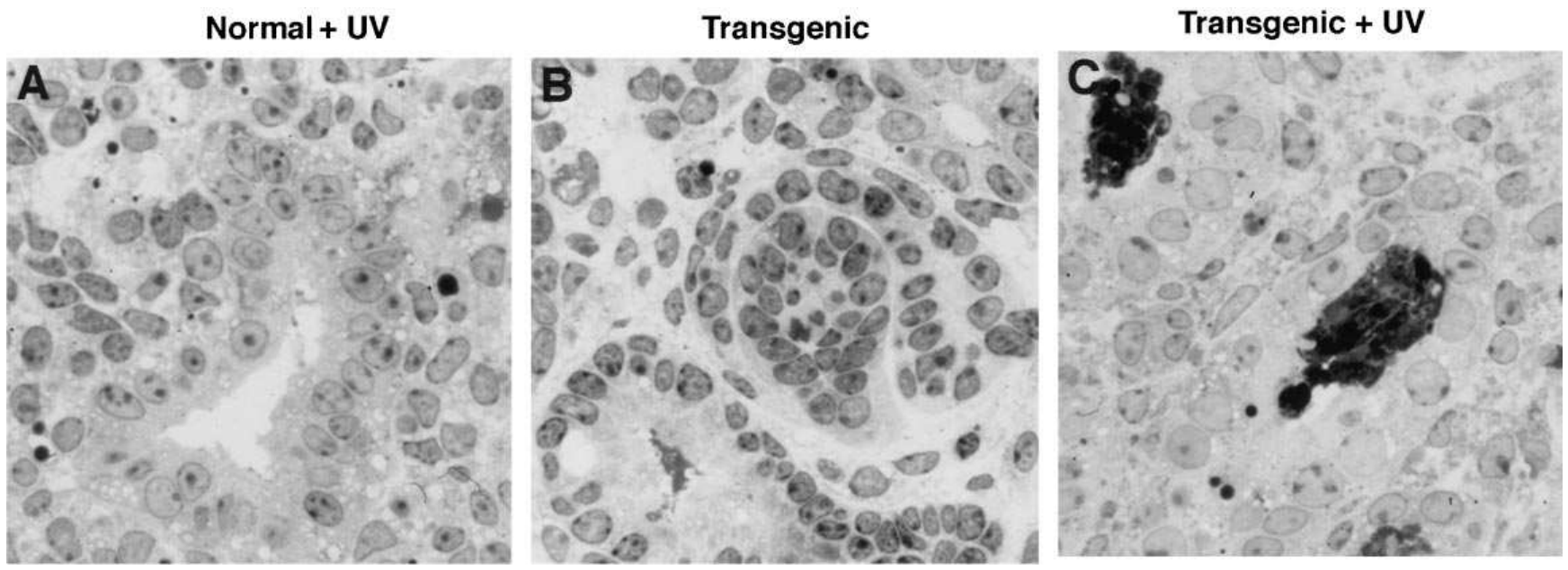

Figure 5. Light micrographs of day 12 fetal kidney cultures after UV irradiation. (A) Nontransgenic fetal kidney irradiated with UV light. (B) Unirradiated HIV-1 transgenic fetal kidney. (C) HIV-1 transgenic fetal kidney after UV irradiation showing dense staining material in regions of tubule formation. Ultrathin $(1 \mu \mathrm{m})$ plastic section, original magnification of 250. 

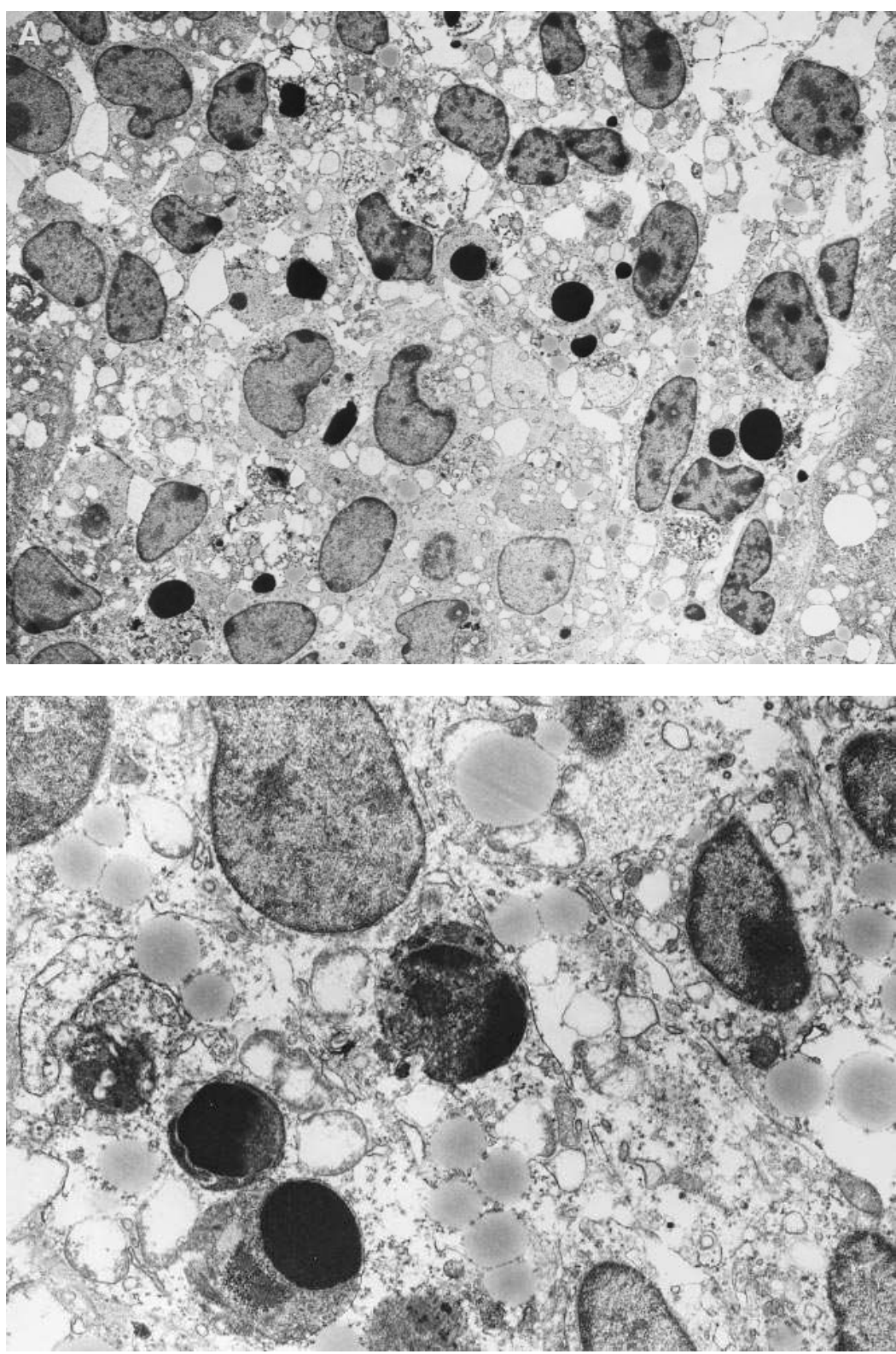

Figure 6. Electron micrographs of HIV-1 transgenic kidney cultures after UV treatment. Nuclei fragmentation and chromatin condensation in a centrifugal pattern on the nuclear envelope are present. $(A)$ Original magnification of 1,600 . $(B)$ Original magnification of 5,000. were typical for HIVAN, including severe microcystic tubular dilatation, proteinacious casts and sclerotic glomeruli (Fig. 7, C and $D$ ). The other animal in the group survived to study termination at $24 \mathrm{wk}$ and was killed with $2+$ proteinuria. Similarly, the transplanted kidney also showed progressive changes as compared with the residual kidney from the transgenic donor, although not to the extent as seen in the animal that was in renal failure.

Kidneys from normal, nontransgenic donors were then transplanted into HIV-1 transgenic mice. The HIV-1 transgenic mice that received transplants from nontransgenic littermates remained healthy for $24 \mathrm{wk}$ after transplant. These animals did not manifest abnormal proteinuria. At the time of death, the histology of the nontransgenic kidney transplant was normal without histological features of HIVAN (Fig. 8).

These results suggest: (a) renal transgene expression is a necessary component in the development of kidney disease, and $(b)$ the milieu associated with systemic transgene expression, in itself, does not appear to cause HIVAN. This does not exclude the possibility, however, that circulating factors may contribute to the rate of progression of this disease in the transgenic animal model or in humans.

\section{Discussion}

Many of the complications of AIDS are thought to be consequences of immunodeficiency or a dysregulation of the immune response. In contrast, Kaposi's sarcoma and AIDS dementia complex are complications that are secondary to cofactors (human herpesvirus 8) or a consequence of a more direct viral effect (tropism for the central nervous system [CNS]) (38-40). The pathological basis for the development of renal disease has been enigmatic. That HIVAN develops at any time during the course of HIV-1 infection, however, suggests that immunodeficiency per se is not the mechanism responsible. As a result, HIVAN has generally been viewed as a disease that occurs as a direct effect of renal cellular HIV-1 infection, a direct effect 

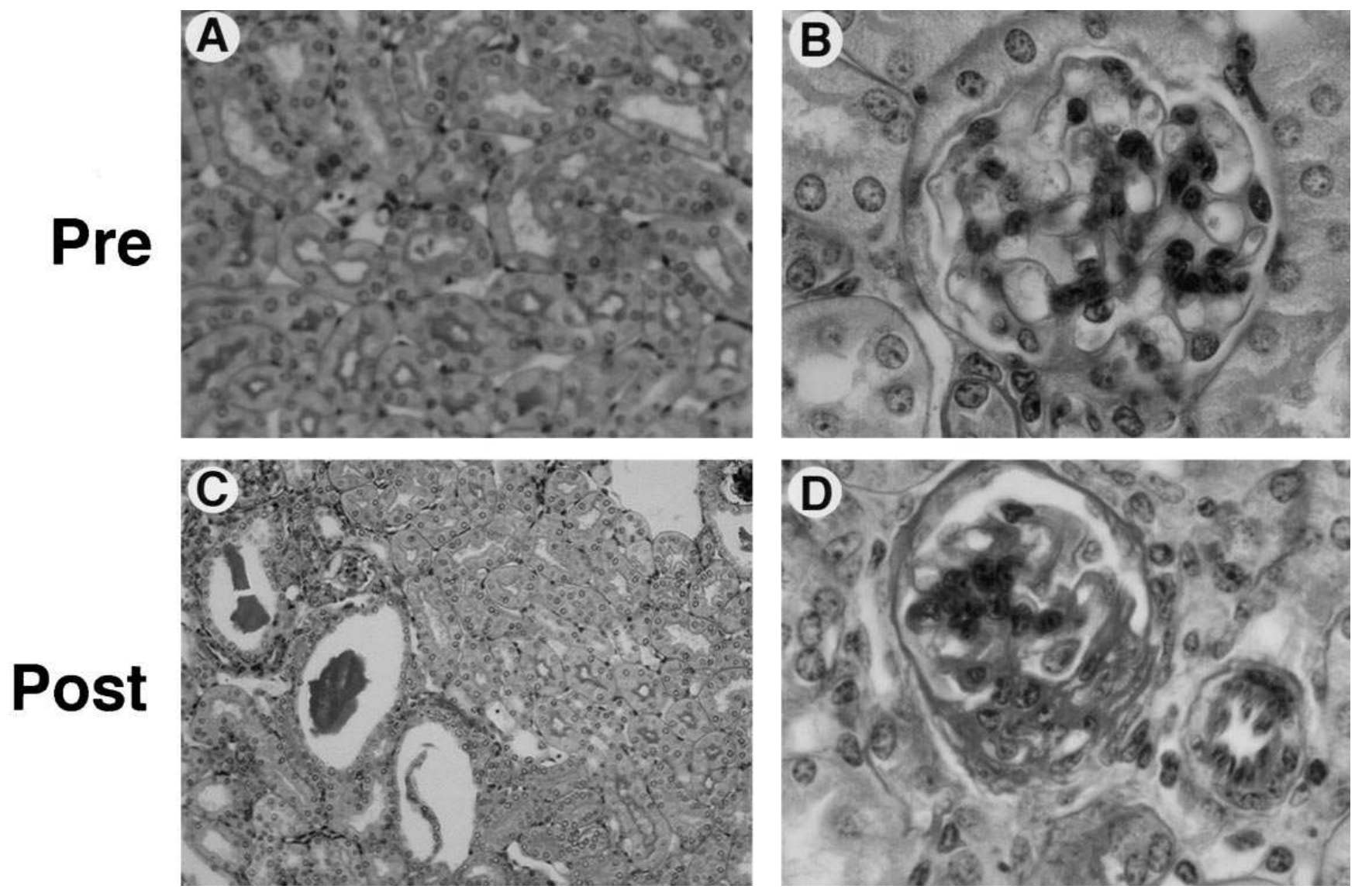

Figure 7. Histology of the residual transgenic kidney of the transgenic mouse and the contralateral kidney that was transplanted into a normal mouse. $(A)$ Residual kidney from the donor transgenic mouse, original magnification of 50. (B) Glomerulus from residual kidney of donor transgenic mouse, original magnification of 250. (C) Transgenic kidney after transplantation into normal mouse, original magnification of 100. $(D)$ Glomerulus from the transgenic kidney after transplantation into normal mouse, original magnification of 250 . Hematoxylin and eosin stain.

of HIV-1 gene products on the kidney, or as an indirect effect of the dysregulated cytokine milieu. The results from the current study, however, suggest that the milieu is less important than the direct expression of the HIV-1 transgene.

While the kidney is not the primary target for HIV-1 infection, it may provide a suitable reservoir for the virus. Recent work by Ray and coworkers has provided evidence that not only do renal cells become infected, but HIVAN patients appear to have viral isolates that have adapted to replication in renal cells (12). The evolution of HIV-1 strains with altered tropism has precedence in AIDS dementia $(39,40)$. AIDS patients with dementia complex have macrophage tropic strains of HIV-1 that have adapted to replication in microglial cells through mutations in envelope as well as the LTR, allowing for viral gene expression in the CNS. Our previous studies with the $\mathrm{Tg} 26$ line of transgenic mice have shown that renal cells are able to express and appropriately process all viral mRNAs (32). Thus, should HIV-1 infect renal cells, there does not appear to be an intracellular block to viral replication.

A potential route of viral entry into kidney cells is currently unknown. The renal tubular epithelial cells are known to be antigen presenting cells and one report suggests some cell types in the kidney may express CD4 $(41,42)$. Non-CD4 routes of viral entry into kidney cells may be possible through the recently identified secondary receptors for HIV-1 infec- tion, CCR-5 (chemokine receptor) and CXCR-4 (LESTR/ Fusin) (43-45). These receptors are important for viral entry into $T$ cells and macrophages and homozygous mutations in the CCR-5 gene are associated with long term survival (46). This recent finding suggests a genetic basis for host resistance to HIV-1 infection $(46,47)$. Based on the racial prevalence of HIVAN in humans, a genetic basis for susceptibility to this HIV complication also appears likely. It remains to be determined, however, whether differences in receptors for viral entry into kidney or differences in the renal sensitivity to the effects of the virus will explain the molecular basis of HIVAN in African Americans.

Thus, in the present manuscript, we demonstrate that renal disease in the murine model of HIVAN is related to renal expression of HIV-1 and is intrinsic to the kidney rather than a bystander phenomenon in response to the systemic milieu or to HIV-1 expression at a distant site. These studies support the hypothesis that the pathogenesis of HIVAN in humans involves a direct effect of HIV-1 expression in renal cells or direct exposure of renal cells to HIV-1 gene products.

\section{Acknowledgments}

We are grateful to Dr. Patricia Wilson for assistance with the in situ hybridizations. We would like to thank Daphne Semet for facilitating 

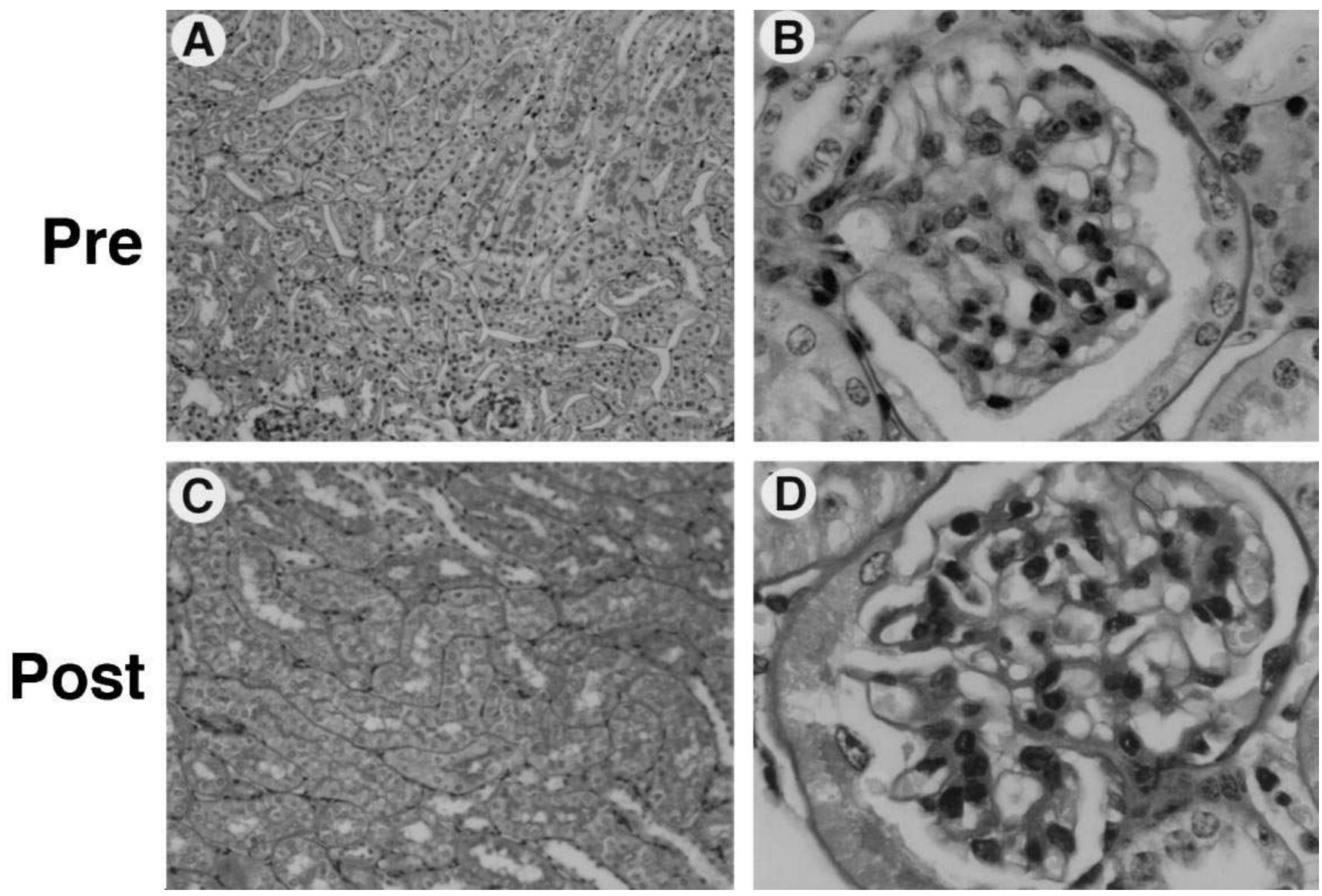

Figure 8. Histology of residual kidney of normal mouse and the contralateral kidney that was transplanted into a transgenic mouse. There were no histological features of HIVAN in the transplanted kidneys although there was evidence of tubular and glomerular hypertrophy, typical of posttransplant, solitary kidney. $(A)$ Residual kidney of the donor normal mouse, original magnification of 100 . $(B)$ Glomerulus from residual kidney of donor mouse, original magnification of 250. (C) Normal kidney after transplant into transgenic mouse, original magnification of 100. $(D)$ Glomerulus from normal kidney after transplant into transgenic mouse, original magnification of 250. Hematoxylin and eosin stain.

the renal transplant studies and the technical assistance of Bob Griffiths. We thank Drs. Wilson and Ruth Abramson for critical review of the manuscript.

This work was funded in part by Public Health Service grant DK50795.

\section{References}

1. Rao, T.K. 1991. Human immunodeficiency virus (HIV) associated nephropathy. Annu. Rev. Med. 42:391-401.

2. Bourgoignie, J.J. 1990. Renal complications of human immunodeficiency virus type 1. Kidney Int. 37:1571-1584.

3. Humphreys, M.H. 1995. Human immunodeficiency virus-associated glomerulosclerosis. Kidney Int. 48:311-320.

4. Simon, D.B., A. Farhi, R. Mahnensmith, and R.P. Lifton. 1996. Inherited susceptibility to HIV nephropathy in African Americans. J. Am. Soc. Nephrol. 7:1343a. (Abstr.)

5. Bourgoignie, J.J., C. Ortiz-Interian, D.F. Green, and D. Roth. 1989. Race, a co-factor in HIV-1 associated nephropathy. Transplant. Proc. 21:38993901.

6. Kimmel, P.L., S.S. VedBrat, P.F. Pierce, W.O. Umana, L. Shepherd, D.A. Verme, R.P. Hirsch, and K.B. Hellman. 1995. Prevalence of viremia in human immunodeficiency virus-infected patients with renal disease. Arch. Intern. Med. 155:1578-1584.

7. Winston, J., P.E. Klotman, and M.E. Klotman. 1996. Plasma HIV-1 RNA in seropositive patients with renal disease. J. Am. Soc. Nephrol. 7:1345a. (Abstr.)

8. Cohen, A.H., N.C.J. Sun, P. Shapshak, and D.T. Imagawa. 1989. Demonstration of human immunodeficiency virus in renal epithelium in HIV-associated nephropathy. Mod. Pathol. 2:125-128.
9. Alpers, C.E., J. McClure, and S.L. Bursten. 1992. Human mesangial cells are resistant to productive infection by multiple strains of human immunodeficiency virus types 1 and 2. Am. J. Kid. Dis. 19:126-130.

10. Green, D.F., L. Resnick, and J.J. Bourgoignie. 1992. HIV infects glomerular endothelial and mesangial but not epithelial cells in vitro. Kidney Int. 41: 956-960.

11. di Belgiojoso, G.B., A. Genderini, L. Vago, C. Parravicini, S. Bertoli, and N. Landriani. 1990. Absence of HIV antigens in renal tissue from patients with HIV-associated nephropathy. Nephrol. Dial. Transplant. 5:489-492.

12. Ray, P.E., D. Henry, L. Xu, L. Dye, J.M. Orenstein, and T. Schuztbank. 1996. Infection and injury of human renal tubular epithelial cells (RETC) by HIV-1 derived from children with HIVAN. J. Am. Soc. Nephrol. 7:13419a (Abstr.)

13. Kimmel, P.L., A. Ferreira-Centeno, T. Farkas-Szallasi, A.A. Abraham, and C.T. Garrett. 1993. Viral DNA in microdissected renal biopsy tissue from HIV infected patients with nephrotic syndrome. Kidney Int. 43:1347-1352.

14. Fauci, A.S., G. Pantaleo, S. Stanley, and D. Weissman. 1996. Immunopathogenic mechanisms of HIV infection. Ann. Intern. Med. 124:654-663.

15. Kopp, J.B., and P.E. Klotman. 1995. Transgenic animal models of renal development and pathogenesis. Am J. Physiol. 269:F601-F620.

16. Ketteler, M., W.A. Border, and N.A. Noble. 1994. Cytokines and L-arginine in renal injury and repair. Am. J. Physiol. 267:F197-F207.

17. Woo, D.D. 1995. Apoptosis and loss of renal tissue in polycystic kidney diseases. N. Engl. J. Med. 333:18-25.

18. Bonventre, J.V. 1993. Mechanisms of ischemic acute renal failure. Kidney Int. 43:1160-1178.

19. Shimizu, A., Y. Masuda, H. Kitamura, M. Ishizaki, Y. Sugisaki, and N. Yamanaka. 1996. Apoptosis in progressive crescentic glomerulonephritis. Lab. Invest. 74:941-951.

20. Gobe, G.C., R. Buttyan, K.R.L. Wyburn, M.R. Etheridge, and P.J. Smith. 1995. Clusterin expression and apoptosis in tissue remodeling associated with renal regeneration. Kidney Int. 47:411-420. 
21. Coles, H.S., Burne, J.F., and M.C. Raff. 1993. Large-scale normal cell death in the developing rat kidney and its reduction by epidermal growth factor. Development (Camb.). 118:777-784.

22. Savill, J. 1994. Apoptosis and the kidney. J. Am. Soc. Nephrol. 5:12-21.

23. Sorenson, C.M., S.A. Rogers, S.J. Korsmeyer, and M.R. Hammerman. 1995. Fulminant metanephric apoptosis and abnormal kidney development in bcl-2-deficient mice. Am. J. Physiol. 268:F73-F81.

24. Veis, D.J., C.M. Sorenson, J.R. Shutter, and S.J. Korsmeyer. 1993. Bcl2-deficient mice demonstrate fulminant lymphoid apoptosis, polycystic kidneys, and hypopigmented hair. Cell. 75:229-240.

25. Laurnet-Crawford, A.G., K. Bernard, S. Muller, Y. Riviere, A.-M. ReyCuille, J.-M. Bechet, L. Montagnier, and A.G. Hovanessian. 1991. The cytopathic effect of HIV is associated with apoptosis. Virology. 185:829-839.

26. Bodi, I.S., A.A. Abraham, and P.L. Kimmel. 1995. Apoptosis in human immunodeficiency virus-associated nephropathy. Am. J. Kid. Dis. 26:286-291.

27. Dickie, P., J. Felser, M. Eckhaus, J. Bryant, J. Silver, N. Marinos, and A.L. Notkins. 1991. HIV-associated nephropathy in transgenic mice expressing HIV-1 genes. Virology. 185:109-119.

28. Kopp, J.B., M.E. Klotman, S.H. Adler, L.A. Bruggeman, P. Dickie, N.J. Marinos, M. Eckhaus, J.L. Bryant, A.L. Notkins, and P.E. Klotman. 1992. Progressive glomerulosclerosis and enhanced renal accumulation of basement membrane components in mice transgenic for HIV-1 genes. Proc. Natl. Acad. Sci. USA. 89:1577-1582.

29. Santoro, T., J.A. Bryant, J. Pellicoro, M.E. Klotman, J.B. Kopp, L.A. Bruggeman, R.R. Franks, A.L. Notkins, and P.E. Klotman. 1994. Growth failure and AIDS-like cachexia syndrome in HIV-transgenic mice. Virology. 201: $147-151$

30. Adler, S.H., L.A. Bruggeman, J.B. Kopp, N. Dorfman, J. Bryant, M. Eckhaus, A.L. Notkins, and P.E. Klotman. 1992. Transcription of HIV-1 genes in transgenic mice is associated with myopathy and myositis. AIDS (Phila.). 8:48a (Abstr.)

31. Kopp, J.B., J.F. Rooney, C. Wohlenberg, N. Dorfman, N.J. Marinos, J.L. Bryant, S.I. Katz, A.L. Notkins, and P. E. Klotman. 1993. Cutaneous disorders and viral gene expression in HIV-1 transgenic mice. AIDS Res. Hum. Retroviruses. 9:267-275.

32. Bruggeman, L.A., M.M. Thomson, P.J. Nelson, J.B. Kopp, J. Rappaport, P.E. Klotman, and M.E. Klotman. 1994. Evidence for tissue-specific regulation of viral expression and mRNA splicing in HIV-1 transgenic mice. Virology. 202:940-948.

33. Franks, R.R., P.E. Ray, C.C. Babbott, J.L. Bryant, A.L. Notkins, T.J. Santoro, and P.E. Klotman. 1995. Maternal-fetal interactions affect growth of human immunodeficiency virus type 1 transgenic mice. Pediatr. Res. 37:56-63.

34. Robert, B., D. Pinson Hyink, P.L. St. John and D.R. Abrahamson. Identification of endothelial precursors in embryonic mouse kidneys. J. Am. Soc.
Nephrol. 6:708a. (Abstr.)

35. Schreck, S., J. Panozzo, J. Milton, C.R. Libertin, and G.E. Woloschak. 1995. The effects of multiple UV exposures on HIV-LTR expression. Photochem. Photobiol. 61:378-382.

36. Quaggin, S.E., H. Yeger, and P. Igarashi. 1997. Antisense oligonucleotides to $c u x-1$, a cut-related homeobox gene, cause increased apoptosis in mouse embryonic kidney cultures. J. Clin. Invest. 99:718-724.

37. Coffman, T.M., S. Geier, S. Ibrahim, R. Griffiths, R. Spurney, O. Smithies, B. Koller, and F. Sanfilippo. 1993. Improved renal function in mouse kidney allografts lacking MHC class I antigens. J. Immunol. 151:425-435.

38. Chang, Y., E. Cesarman, M.S. Pessin, F. Lee, J. Culpepper, D.M. Knowles, and P.S. Moore. 1994. Identification of new human herpesvirus-like DNA sequences in AIDS-associated Kaposi's sarcoma. Science (Wash. DC). 266: 1865-1869.

39. Cauley, K., and I.M. Verma. 1994. Kappa B enhancer binding complexes that do not contain NF-kappa B are developmentally regulated in mammalian brain. Proc. Natl. Acad. Sci. USA. 91:390-394.

40. Buzy, J.M., L.M. Lindstrom, M.C. Zink, and J.E. Clements. 1995. HIV-1 in the developing CNS: Developmental differences in gene expression. Virology. 210:361-371.

41. Karlsson-Parra, A., E. Dimeny, B. Fellstrom, and L. Klareskog. 1989. HIV receptors (CD4 antigen) in normal human glomerular cells. N. Engl. J. Med. 320:741.

42. Rubin-Kelley, V.E., and A.M. Jevnikar. 1991. Antigen presentation by renal tubular epithelial cells. J. Am. Soc. Nephrol. 2:13-26.

43. Dragic, T., V. Litwin, G.P. Allaway, S.R. Martin, Y. Huang, K.A. Nagashima, C. Cayanan, P.J. Maddon, R.A Koup, J.P. Moore, and W.A. Paxton. 1996. HIV-1 entry into CD4+ cells is mediated by the chemokine receptor CCCKR-5. Nature (Lond.). 381:667-673.

44. Deng, H., R. Liu, W. Ellmeier, S. Choe, D. Unutmaz, M. Burkhart, P. DiMarzio, S. Marmon, R.E. Sutton, C.M. Hill, et al. 1996. Identification of a major co-receptor for primary isolates of HIV-1. Nature (Lond.). 381:661-666.

45. Feng, Y., C.C. Border, P.E. Kennedy, and E.A. Berger. 1996. HIV-1 entry cofactor: function cDNA cloning of a seven-transmembrane, $\mathrm{G}$ protein-coupled receptor. Science (Wash. DC). 272:872-877.

46. Liu, R, W.A. Paxton, S. Choe, D. Ceradini, S.R. Martin, R. Horuk, M.E MacDonald, H. Stuhlmann, R.A. Koup, and N.R. Landau. 1996. Homozygous defect in HIV-1 coreceptor accounts for resistance of some multiply-exposed individuals to HIV-1 infection. Cell. 86:367-377.

47. Dean, M., M. Carrington, C. Winkler, G.A. Huttley, M.W. Smith, R. Allikmets, J.J. Goedert, S.P. Buchbinder, E. Vittinghoff, E. Gomperts, et al. 1996. Genetic restriction of HIV-1 infection and progression to AIDS by a deletion allele of the CKR5 structural gene. Science (Wash. DC). 273:1856-1862. 